\title{
Dairy calf management-A comparison of practices and producer attitudes among conventional and organic herds
}

\author{
J. A. Pempek, G. M. Schuenemann, E. Holder, and G. G. Habing ${ }^{1}$ \\ Department of Veterinary Preventive Medicine, College of Veterinary Medicine, The Ohio State University, Columbus 43210
}

\begin{abstract}
Dairy calves are at high risk for morbidity and mortality early in life. Understanding producer attitudes is important for implementation of best management practices to improve calf health. The objectives of this study were to evaluate usage frequency and producer attitudes on key calf management practices between conventional and organic dairy operations. A cross-sectional survey was mailed to conventional and organic dairy producers in Ohio and Michigan that included questions on cow-calf separation, colostrum management, and vaccination use. The overall survey response rate was $49 \%(727 / 1,488) ; 449$ and 172 conventional and organic producer respondents, respectively, were included in the final analysis. Binary, cumulative, and multinomial logistic regression models were used to test differences within and between herd types for management practices and producer attitudes. The majority of conventional $(64 \%, 279 / 439)$ producers reported separating the calf from the dam 30 min to $6 \mathrm{~h}$ after birth. More organic $(34 \%, 56 / 166)$ than conventional $(18 \%$, 80/439) producers reported separation 6 to $12 \mathrm{~h}$ after birth, and organic producers were more likely to agree time before separation is beneficial. Few conventional $(10 \%, 44 / 448)$ and organic $(3 \%, 5 / 171)$ producers reported measuring colostrum quality. Most conventional producers $(68 \%, 304 / 448)$ hand-fed the first feeding of colostrum, whereas the majority of organic producers $(38 \%, 69 / 171)$ allowed calves to nurse colostrum. Last, $44 \%(188 / 430)$ of conventional producers reported vaccinating their calves for respiratory disease, compared with $14 \%$ (22/162) of organic producers; organic producers were more likely to perceive vaccines as ineffective and harmful to calf health. Thus, the usage frequency and perceived risks and benefits of calf management practices vary considerably between conventional and organic dairy producers. These findings provide help-
\end{abstract}

Received January 6, 2017.

Accepted May 5, 2017.

${ }^{1}$ Corresponding author: habing.4@osu.edu ful information to understand decision making at the herd level regarding key calf management and health practices, regardless of production systems.

Key words: calf health, cow-calf separation, colostrum, vaccination

\section{INTRODUCTION}

Young dairy calves are at high risk for morbidity and mortality (Uetake, 2013). The most common reasons for deaths among preweaned dairy heifer calves are neonatal calf diarrhea and bovine respiratory disease (USDA, 2010), with 57 and $23 \%$ of deaths occurring due to these diseases, respectively (USDA, 2010). Thus, producer implementation of best management practices is vitally important to ensure calf health and welfare (Windeyer et al., 2014).

Understanding dairy producers' current management practices and attitudes is important to identify barriers toward implementation of best management practices. Management practices have been reported to differ between conventional and organic dairy operations (Zwald et al., 2004; Habing et al., 2016), and the barriers toward implementation are likely to vary between producer types; however, no studies to date have compared specific management practices that influence calf health between operation types.

The implementation of best management practices at the herd level is influenced by producer attitudes (Rahelizatovo and Gillespie, 2004; Gillespie et al., 2007). An attitude can be defined as a positive or negative response toward an idea or concept (Willock et al., 1999) and is a predictor of future behavior (Kraus, 1995). For specific management practices to be sustainable, they must also balance the values of relevant stakeholders (e.g., producers, consumers). Previous research suggests producer willingness to adopt best management practices varies among dairy producers (Rahelizatovo and Gillespie, 2004). This highlights a need for further research efforts to gain a better understanding of producer attitudes that might affect decisions related to the implementation of key calf management practices to safeguard calf health. 
Some of the management practices that affect calf health include cow-calf separation (Whittington and Windsor, 2009), colostrum management (Godden, 2008), and vaccination use (McGuirk, 2008). Most dairy farms separate the calf from the dam within hours of birth, and the calf is placed in individual or group housing until weaned from milk (USDA, 2016). Early separation is often practiced, as research has shown it to reduce calves' risk of exposure to environmental pathogens (e.g., Johne's transmission; Whittington and Windsor, 2009), ensure successful colostrum delivery (Furman-Fratczak et al., 2011), and reduce potential cow-calf bonding and behavioral distress at separation (Weary and Chua, 2000); however, this practice remains an area of public concern worldwide (Boogaard et al., 2010; Ventura et al., 2016). In addition, colostrum quality, quantity, and timing of feeding relative to calf birth has long been associated with calf survival and health, and measurement of colostrum quality before feeding newborn calves is recommended as a best practice (Godden, 2008). Colostrum delivery method (e.g., hand-fed, nurse the dam) can also affect the health and welfare of the calf, but these results are less conclusive (Weary and Chua, 2000; Svensson et al., 2003). Furthermore, a vaccination program is key to prevent diseases, and thus, the productivity of future replacement heifers (McGuirk, 2008). Their use also extends to improve food safety, as vaccination programs reduce the risk for infectious diseases and the subsequent need for antibiotic treatments (Roth, 2011).

Thus, the objectives of our study were to assess the usage frequency of selected calf management practices for conventional and organic dairy operations, and investigate attitudinal differences between producers related to calf health and management. We hypothesized that the usage frequency and producer attitudes would differ between conventional and certified organic dairy operations. We also hypothesized that producer attitudes would be associated with the implementation of specific calf management practices.

\section{MATERIALS AND METHODS}

\section{Study Design and Herd Selection}

A cross-sectional study of conventional and organic dairy producers in Ohio and Michigan was conducted in 2015. Herds eligible for participation in the study included all licensed grade A and certified organic dairy operations that reported raising their heifer calves for replacement on their property; herd demographics (e.g., herd size, grade status) were not available before farm selection. Lists of grade A dairy farms in each state (Ohio, $\mathrm{n}=2,288$; Michigan, $\mathrm{n}=1,681$ ) were procured from the Departments of Agriculture of Ohio and Michigan, respectively. A total of 600 usable responses from conventional producers were targeted to provide sufficient power $(\beta=0.20)$ to demonstrate a significant $(\alpha=0.05)$ difference between groups, assuming the proportions of producers reporting use of a specific management practice across the 2 hypothetical comparison groups were 70 and $80 \%$. Assuming a 50\% response rate, a stratified random sample of 1,200 conventional operations (600 per state) was selected using a random number generator (Microsoft Excel, Redmond, WA). Further, all organic dairy farms listed on the USDA National Organic Program (NOP) website (https:// organic.ams.usda.gov/Integrity/) were selected, including 250 and 71 certified organic dairy producers from Ohio and Michigan, respectively. Thus, a total of 1,521 surveys were mailed to conventional and organic dairy producers across Ohio and Michigan.

\section{Survey Development and Delivery}

This self-administered survey was developed in consultation with veterinarians, dairy producers, and calf experts from The Ohio State University. A pilot study was first conducted with 6 producers and veterinarians to improve clarity of survey questions. The final draft of the survey consisted of 71 questions, which included questions on calf health and antimicrobial use; results pertaining to antimicrobial use are reported in Habing et al. (2016). The results reported here include 27 survey questions that focused on specific calf management practices, including timing of cow-calf separation, colostrum delivery, measurement of colostrum quality, and vaccination for respiratory disease. Survey questions were also developed to address producer attitudes toward the risks and benefits of these practices, in addition to perceived monetary cost, effectiveness, and feasibility for implementation. A copy of the survey questions have been included as supplemental material (https://doi.org/10.3168/jds.2017-12565). Survey materials were approved by The Ohio State University, Human Subjects Institutional Review Board (Approval no. 2014E0265).

Survey delivery was modeled after the tailored design method (Dillman et al., 2009), and multiple mailings (e.g., introductory postcard, survey packet, reminder postcard) were sent to selected producers to increase total response rate. In short, the introductory postcard was first sent to inform participants about the study on August 11, 2014. Producers then received the survey packet on August 24, 2014, which included an introductory letter, consent form, survey, prepaid return 
envelope, and $\$ 4$ cash as an incentive for survey return. The introductory letter requested the individual on the farm most familiar with calf care to complete the survey. Lastly, a reminder/thank you postcard was sent to all participants on September 12, 2014, to either encourage or thank them for their participation in the study. English and Spanish versions of all materials were mailed to each recipient.

\section{Statistical Analysis}

Descriptive statistics were calculated for attitude variables among conventional and organic dairy producers. Total responses may differ across questions within and between categories due to producer non-response. To avoid biased estimates for the inference population, sampling weights within each stratum, including state (Ohio or Michigan) and herd type (conventional or organic) were calculated (Dargatz and Hill, 1996). The SURVEYFREQ procedure (SAS version 9.4, SAS Institute Inc., Cary, NC) was used to calculate weighted proportions, standard errors, and confidence intervals for proportions. Exact (Clopper-Pearson) confidence intervals were calculated for proportions with numerators less than or equal to 10 (Clopper and Pearson, 1934). State and herd type (where applicable) were specified in the STRATUM statement. Numerators and denominators for each estimate are additionally reported alongside weighted estimates.

To statistically compare differences between conventional and organic producer groups for calf management practices and attitudes, binary logit, cumulative proportional odds, and multinomial logistic regression models were used for binomial (measurement of colostrum quality, use of vaccinations), ordinal (herd size, maternity housing, timing of cow-calf separation), and nominal (colostrum delivery method, herd type) outcome variables, respectively. The 5-point Likert item response scale (strongly agree, agree, neutral, disagree, strongly disagree; 1 to 5 , respectively) for attitude variables was collapsed into 3 levels (agree, neutral, disagree). The SURVEYLOGISTIC procedure was used to test differences between producer groups. State (Ohio or Michigan) was forced into each model to account for potential differences in demographics or herd practices between the 2 states. Herd size was significantly associated with colostrum management practices and, thus, was included in each model pertaining to colostrum quality. The score test was used to test the proportional odds assumption for all cumulative logistic regression models (Hosmer et al., 2013). The Wald Chi-squared test was used to assess the difference between conventional and organic herds.
To assess the relationship between conventional producer attitudes and early separation, timing of cow-calf separation (early, delayed, or late separation) was used as the dependent variable in a multivariable proportional odds cumulative logistic regression model. The primary independent variables of interest were conventional producer survey responses that captured attitudes on the importance of increased time before separation for cow and calf, cow licking calf, natural calving process, and maternity pen design or management. The 6 -item scale $(<30 \mathrm{~min}, 30 \mathrm{~min}$ to 6 h, 6-12 h, 12-18 h, 18-24 h, or $>24 \mathrm{~h}$ ) for timing of cow-calf separation was collapsed into 3 levels (early, delayed, or late), and the 5-point Likert item response scale (strongly agree, agree, neutral, disagree, strongly disagree) for attitudinal variables was collapsed into 3 levels (agree, neutral, disagree) for the purpose of this analysis. Correlation between levels of agreement were evaluated using the Pearson correlation coefficient (PROC CORR procedure). There was a significant correlation between responses for the 6 attitude variables; thus, only a single attitude variable was included in the model at a time. State was forced into each model, and variables where $P<0.05$ were considered significant.

\section{RESULTS}

\section{Survey Response Rate}

Of the 1,521 (1,200 conventional; 321 certified organic) dairy farms in the initial sample, 26 surveys could not be delivered to conventional producers, and 7 surveys could not be delivered to organic producers due to incorrect mailing addresses. To be included in the study, respondents were screened to ensure they met predefined eligibility criteria, such as raising preweaned heifer calves on farm property and identification of herd size (e.g., lactating and dry cows) and state of residency. Seventy-four conventional producers and 24 organic producers reported not raising preweaned heifer calves on farm property. Herd size was not reported by 7 and 3 conventional and organic producers, respectively, and 3 conventional producers did not specify state of residency. In total, $49 \%(727 / 1,488)$ of surveys were returned, including $43 \%(474 / 1,100)$ from conventional producers and 51\% (147/290) from organic producers. Twenty-seven producers from the grade-A list (e.g., conventional operations) self-identified as being organic (e.g., producing organically certified milk or calves), and 2 producers from the organic list self-identified as being conventional operations, resulting in 449 and 172 survey responses from conventional and organic dairy producers, respectively. 


\section{Herd Characteristics}

The majority of survey respondents identified as herd owners; $87 \%(398 / 459)$ of conventional and 95\% $(166 / 174)$ of organic survey respondents reported that they owned the dairy operation. Herd size, maternity pen design, colostrum delivery method, and vaccination practices differed between conventional and organic herds (Table 1). For example, $56(252 / 449)$ and 39\% $(177 / 449)$ of conventional producer respondents were from small $(<100$ cows $)$ and medium-sized (100-499 cows) herds, respectively, whereas $94 \%$ (160/171) of organic producer respondents were from small herds of $<100$ cows. Forty-two percent $(185 / 446)$ of herds from conventional farms reported use of individual calving pens, and $26(117 / 446)$ and 17\% (76/446) reported having small (2 to 4 cows at one time) or large (more than 4 cows at one time) group calving pens, respectively. Organic producers reported similar use $(38 \%, 64 / 169)$ of individual calving pens compared with conventional producers; however, $38 \%(66 / 169)$ of organic producers reported having other calving pen designs (other was predominantly defined as pasture). Most conventional producers $(68 \%, 304 / 448)$ reported hand-feeding newborn calves the first colostrum feeding, compared with $30 \%(50 / 171)$ of organic producers. In contrast, more organic $(38 \%, 69 / 171)$ than conventional $(13 \%, 56 / 448)$ producers reported leaving calves with the dam to suckle the first feeding of colostrum. Forty-four (188/430) and $14 \%(22 / 162)$ of conventional and organic producers, respectively, reported vaccinating their calves for respiratory disease. Lastly, producer-reported mortality rates (Habing et al., 2016) did not influence $(P>0.05)$ the specific management practices of interest (e.g., cowcalf separation, colostrum management, or vaccination use) in our study.

\section{Cow-Calf Separation}

Timing of Cow-Calf Separation. The duration of time before cow-calf separation differed $(P<0.001)$ between conventional and organic herds (Figure 1). For instance, the majority $(64 \%, 279 / 439)$ of conventional producers reported separating the calf from the dam 30 min to $6 \mathrm{~h}$ after birth. In contrast, $42 \%(66 / 166)$ of organic producers separated the calf from the dam $30 \mathrm{~min}$ to $6 \mathrm{~h}$ after birth, and 34\% (56/166) reported separation 6 to $12 \mathrm{~h}$ after birth. Fewer conventional and organic producers reported separating the calf from the dam $>12 \mathrm{~h}$ after birth; however, twice as many organic producers reported separation 12 to 18,18 to 24 , and $>24 \mathrm{~h}$ after birth compared with conventional producers. The duration of time before cow-calf separation also differed $(P<0.0001)$ by herd size; large herds were more likely than small herds to practice early separation.

Attitudes on Cow-Calf Separation Practices. Producer attitudes differed $(P<0.01)$ between conventional and organic producers with regard to cowcalf separation on 3 of 6 attitudinal response variables (Table 2). The majority $(62 \%, 105 / 170)$ of organic producers agreed that more than $2 \mathrm{~h}$ before separation is beneficial for the health of the dam, compared with $32 \%(143 / 444)$ of conventional producer respondents.

Table 1. Percentage (SE) of survey respondents from conventional and organic dairy operations in Michigan and Ohio with the following herd characteristics

\begin{tabular}{|c|c|c|c|c|c|}
\hline \multirow[b]{2}{*}{ Item } & \multicolumn{2}{|c|}{ Conventional } & \multicolumn{2}{|c|}{ Organic $^{1}$} & \multirow[b]{2}{*}{$P$-value } \\
\hline & Percent (SE) & No. & Percent (SE) & No. & \\
\hline \multicolumn{6}{|l|}{ Number of cows } \\
\hline$<100$ & $56.2(2.3)$ & $252 / 449$ & $94.4(1.8)$ & $160 / 171$ & $<0.0001$ \\
\hline $100-499$ & $39.4(2.3)$ & $177 / 449$ & $4.9(1.7)$ & $10 / 171$ & \\
\hline$\geq 500$ & $4.4(1.0)$ & $20 / 449$ & 0.7 & $1 / 171$ & \\
\hline \multicolumn{6}{|l|}{ Maternity housing } \\
\hline Individual & $41.5(2.3)$ & $185 / 446$ & $37.7(4.0)$ & $64 / 169$ & 0.0006 \\
\hline Group (2-4 cows) & $26.2(2.1)$ & $117 / 446$ & $11.6(2.7)$ & $18 / 169$ & \\
\hline Group ( $>4$ cows) & $17.1(1.8)$ & $76 / 446$ & $13.2(2.8)$ & $21 / 169$ & \\
\hline Other & $15.2(1.7)$ & $68 / 446$ & $37.6(4.0)$ & $66 / 169$ & \\
\hline \multicolumn{6}{|l|}{ Colostrum delivery } \\
\hline Suckle dam & $12.6(1.6)$ & $56 / 448$ & $38.3(3.9)$ & $69 / 171$ & 0.05 \\
\hline Hand-fed & $67.8(2.2)$ & $304 / 448$ & $29.7(3.7)$ & $50 / 171$ & \\
\hline Both & $17.2(1.8)$ & $77 / 448$ & $29.8(3.7)$ & $48 / 171$ & \\
\hline Other & $2.4(0.7)$ & $11 / 448$ & 2.3 & $4 / 171$ & \\
\hline \multicolumn{6}{|l|}{ Vaccination } \\
\hline Yes & $43.6(2.4)$ & $188 / 430$ & $14.4(3.0)$ & $22 / 162$ & $<0.0001$ \\
\hline No & $56.4(2.4)$ & $242 / 430$ & $85.6(3.0)$ & $140 / 162$ & \\
\hline
\end{tabular}

${ }^{1}$ Herds that indicated producing organically certified milk or calves were classified as organic. 


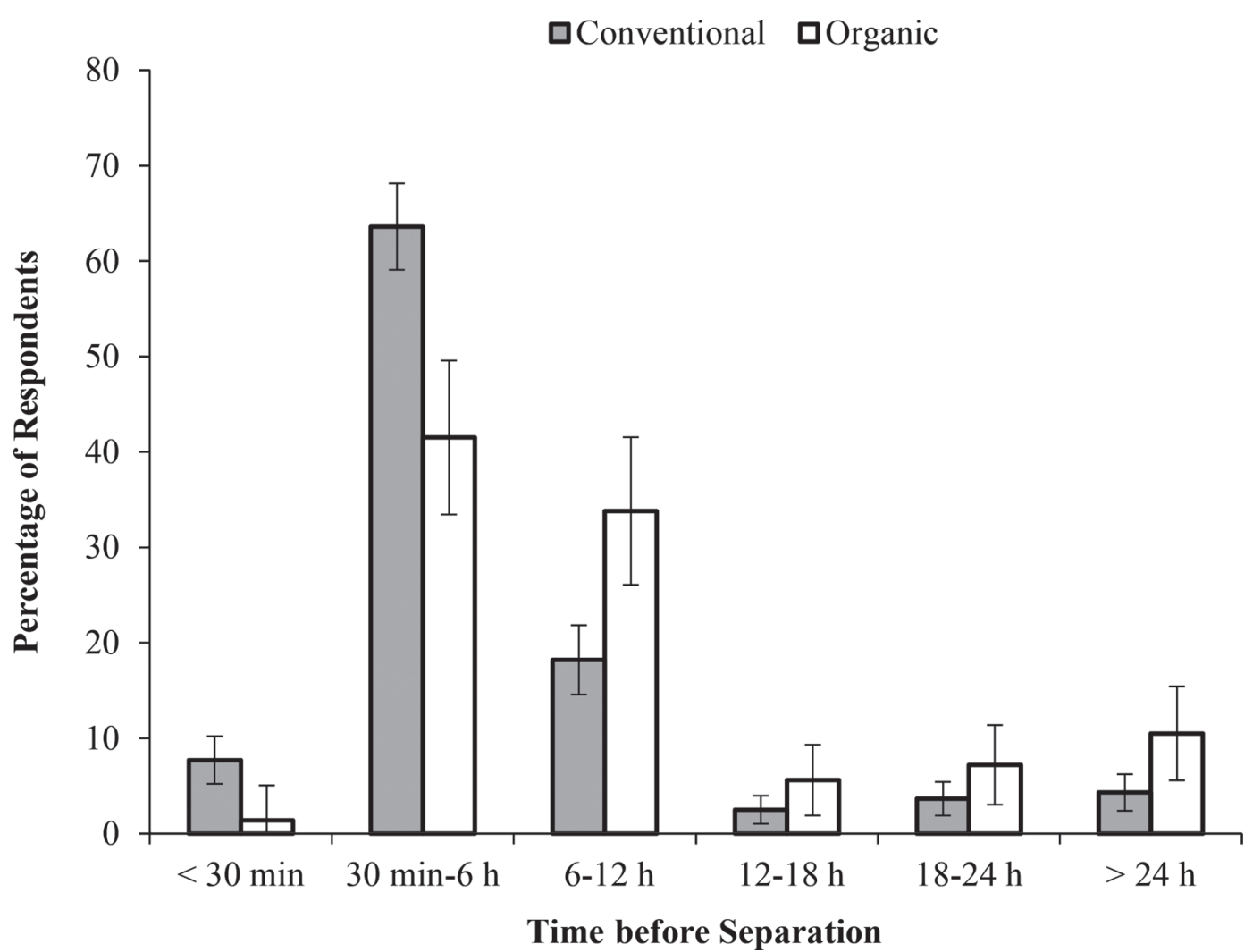

Figure 1. Percentage $( \pm \mathrm{SE})$ of conventional and organic dairy producers that reported time before cow-calf separation being less than 30 min, 30 min to $6 \mathrm{~h}, 6$ to $12 \mathrm{~h}, 12$ to $18 \mathrm{~h}, 18$ to $24 \mathrm{~h}$, or greater than $24 \mathrm{~h}$. The amount of time prior to cow-calf separation significantly differed $(P<0.0001)$ between conventional and organic dairy producers.

Similarly, a larger percentage of organic $(74 \%, 129 / 171)$ than conventional $(48 \%, 210 / 442)$ producers agreed that more than $2 \mathrm{~h}$ before separation is beneficial for the health of the calf. Thus, organic producers were more likely than conventional producers to agree that postponing separation ( $>2 \mathrm{~h}$ after birth) is beneficial to the health of both the dam and calf. Conventional producers had twice the odds of agreeing that separation within $1 \mathrm{~h}$ after birth is due to management or facility design (e.g., calving pen design; Table 2), and this finding remained true when only small $(<100$ cows) conventional and organic herds were considered.

Table 2. Level of agreement between survey respondents from conventional (CON) and organic (ORG) operations on statements pertaining to cow-calf separation practices

\begin{tabular}{|c|c|c|c|c|c|c|c|c|}
\hline Item & $\begin{array}{l}\text { Farm } \\
\text { type }\end{array}$ & \multicolumn{7}{|c|}{ Level of agreement (\%) } \\
\hline $\begin{array}{l}\text { More than } 2 \mathrm{~h} \text { before separation is beneficial for } \\
\text { the dam. }\end{array}$ & $\mathrm{CON}$ & 444 & 0.28 & $(0.20,0.41)$ & $<0.0001$ & 32 & 39 & 28 \\
\hline \multirow{2}{*}{$\begin{array}{l}\text { It is important for the cow to lick the calf before } \\
\text { separation. }\end{array}$} & $\mathrm{CON}$ & 447 & 0.57 & $(0.22,1.5)$ & 0.24 & 92 & 7 & 1 \\
\hline & ORG & 171 & Referent & & & 96 & 4 & 0 \\
\hline $\begin{array}{l}\text { We want the calving process to be as natural as } \\
\text { possible. }\end{array}$ & $\mathrm{CON}$ & 447 & 0.37 & $(0.10,1.3)$ & 0.11 & 94 & 5 & 1 \\
\hline $\begin{array}{l}\text { Calves spend more time with the dam because } \\
\text { calving is unobserved. }\end{array}$ & ORG & 170 & Referent & & & 47 & 34 & 19 \\
\hline \multirow{2}{*}{$\begin{array}{l}\text { Separation within } 1 \mathrm{~h} \text { after birth is due to calving } \\
\text { pen design. }\end{array}$} & $\mathrm{CON}$ & 439 & 2.2 & $(1.4,3.4)$ & 0.0007 & 10 & 27 & 63 \\
\hline & ORG & 169 & Referent & & & 1 & 20 & 80 \\
\hline \multirow{2}{*}{$\begin{array}{l}\text { More than } 2 \mathrm{~h} \text { before separation is beneficial for } \\
\text { the calf. }\end{array}$} & $\mathrm{CON}$ & 442 & 0.36 & $(0.23,0.55)$ & $<0.0001$ & 48 & 28 & 24 \\
\hline & ORG & 171 & Referent & & & 75 & 19 & 6 \\
\hline
\end{tabular}

${ }^{1}$ Odds ratios reflect the odds of a higher level of agreement in conventional producers relative to organic producers. 
The difference in level of agreement between conventional and organic producers was minimal with regard to the importance of naturalness during and after calving; the majority of conventional and organic producers agreed that the calving process should be as natural as possible (conventional: $94 \%, 419 / 447$; organic: $98 \%$, $168 / 171$ ), and the dam should be able to lick the calf before separation (conventional: 92\%, 409/447; organic: $96 \%, 164 / 171)$.

\section{Predictors of Early Cow-Calf Separation Among Conventional Producers}

To identify specific attitudes associated with early cow-calf separation among conventional producers, producers who reported separating the calf from the dam were categorized by early (birth to $6 \mathrm{~h}$ ), delayed $(6-18 \mathrm{~h})$, and late $(>18 \mathrm{~h}$ after birth) separation timing (Figure 1). Because we noted a significant $(P<0.05)$ correlation between producer responses to the 6 attitude questions pertaining to cow-calf separation, only 1 response variable was included in the model at a time; thus, the final model included 1 of the 6 attitude questions and the respondent's state of residence. Among conventional producers, early cow-calf separation was associated $(P<0.05)$ with 4 of 6 response variables based on an ordinal logistic regression model (Table 3 ). Conventional producers were 4.5 times more likely to practice early cow-calf separation if they disagreed that more than $2 \mathrm{~h}$ before separation is beneficial for the dam $(\mathrm{OR}=4.5,95 \% \mathrm{CI}=2.3-8.5)$. In accordance, conventional producers who practiced early cow-calf separation were 9 times more likely to disagree that $2 \mathrm{~h}$ before separation is important for the calf $(\mathrm{OR}=$ 9.3, 95\% CI $=4.3-20.3)$. Further, among conventional producers, early separation was significantly associated with maternity pen design; conventional producers who agreed that separation within $1 \mathrm{~h}$ after birth occurs due to the calving pen design had 5 times the odds of practicing early separation $(P=0.003)$. In addition, the majority of producers $(45 \%, 80 / 177)$ who disagreed that separation within $1 \mathrm{~h}$ after birth occurs due to the calving pen design reported using individual calving pens.

\section{Colostrum Quality and Delivery Method}

Conventional and organic producer respondents were not significantly different $(P=0.45)$ in their response to the question, "Does your operation routinely use instruments such as a colostrometer or refractometer to measure the quality of colostrum fed to newborn calves?" Regardless of herd type (e.g., conventional versus organic), the vast majority of producers reported they do not measure colostrum quality. Specifically, only $10(44 / 448)$ and $3 \%(5 / 171)$ of conventional and organic producers, respectively, reported measuring colostrum quality before feeding newborn calves. However, among conventional and organic producers that reported measuring quality, $91(40 / 44)$ and 40\% (2/5), respectively, hand-fed colostrum. Measurement of colostrum quality differed across herd sizes $(P<0.0001$; Figure 2). Among large conventional herds, $25 \%(5 / 20)$ reported measuring colostrum quality, compared with only $3 \%(7 / 251)$ of small conventional herds. Fewer certified organic producer respondents reported measuring colostrum quality, with $14 \%(1 / 10)$ and $2 \%(3 / 160)$ from medium and small herds, respectively.

\section{Attitudes on Measuring Colostrum Quality}

The magnitude of the difference between conventional and organic producers with regard to measuring colostrum quality varied by attitudinal statement (Table 4). For instance, 45\% (188/418) of conventional producers agreed that measuring colostrum quality is

Table 3. Results for 6 multivariable ordinal regression models that depict the association between early ( $<6 \mathrm{~h}$ after birth) cow-calf separation and attitudes among conventional producers

\begin{tabular}{|c|c|c|c|c|}
\hline \multirow[b]{2}{*}{ Item } & \multicolumn{4}{|c|}{ Odds ratio (OR) estimates for early cow-calf separation } \\
\hline & $\mathrm{N}$ & $\mathrm{OR}^{1}$ & $95 \%$ CI & $P$-value \\
\hline It is important for the cow to lick the calf before separation. ${ }^{2}$ & 438 & - & - & - \\
\hline We want the calving process to be as natural as possible. & 438 & 1.1 & $(0.11,11.7)$ & 0.10 \\
\hline Calves spend more time with the dam because calving is unobserved. & 433 & 1.1 & $(0.64,1.8)$ & 0.95 \\
\hline Separation within $1 \mathrm{~h}$ after birth is due to calving pen design. & 430 & 0.19 & $(0.06,0.56)$ & 0.003 \\
\hline
\end{tabular}


Table 4. Level of agreement between survey respondents from conventional (CON) and organic (ORG) operations on statements pertaining to measuring colostrum quality

\begin{tabular}{|c|c|c|c|c|c|c|c|c|}
\hline Item & $\begin{array}{l}\text { Farm } \\
\text { type }\end{array}$ & \multicolumn{7}{|c|}{ Level of agreement (\%) } \\
\hline Job training is good enough to measure colostrum quality. & ORG & 153 & Referent & & & 27 & 64 & 9 \\
\hline \multirow{2}{*}{$\begin{array}{l}\text { Measuring colostrum quality is useful to make decisions } \\
\text { on feeding calves colostrum. }\end{array}$} & $\mathrm{CON}$ & 418 & 1.8 & $(1.2,2.8)$ & 0.008 & 45 & 50 & 5 \\
\hline & ORG & 153 & Referent & & & 23 & 66 & 11 \\
\hline Equipment for measuring colostrum is expensive. & $\mathrm{CON}$ & 411 & 0.92 & $(0.62,1.5)$ & 0.82 & 24 & 63 & 13 \\
\hline Measuring colostrum quality is time consuming. & ORG & 149 & Referent & & & 29 & 67 & 4 \\
\hline
\end{tabular}

${ }^{1}$ Odds ratios (OR) reflect the odds of a higher level of agreement in conventional producers relative to organic producers.

useful to make decisions on feeding calves colostrum, in comparison to $24 \%(35 / 153)$ of organic producers. Stated differently, conventional producers were nearly twice as likely to agree that measuring colostrum quality is useful compared with organic producers (Table 4). Among conventional producers who reported measuring colostrum quality, nearly all respondents $(95 \%, 41 / 43)$ agreed with this statement. However, $39 \%(147 / 375)$ of conventional producers who reported they do not measure colostrum quality still agreed that the measurement was useful; these producers responded neutrally as to whether they believed it was time-consuming or ex-

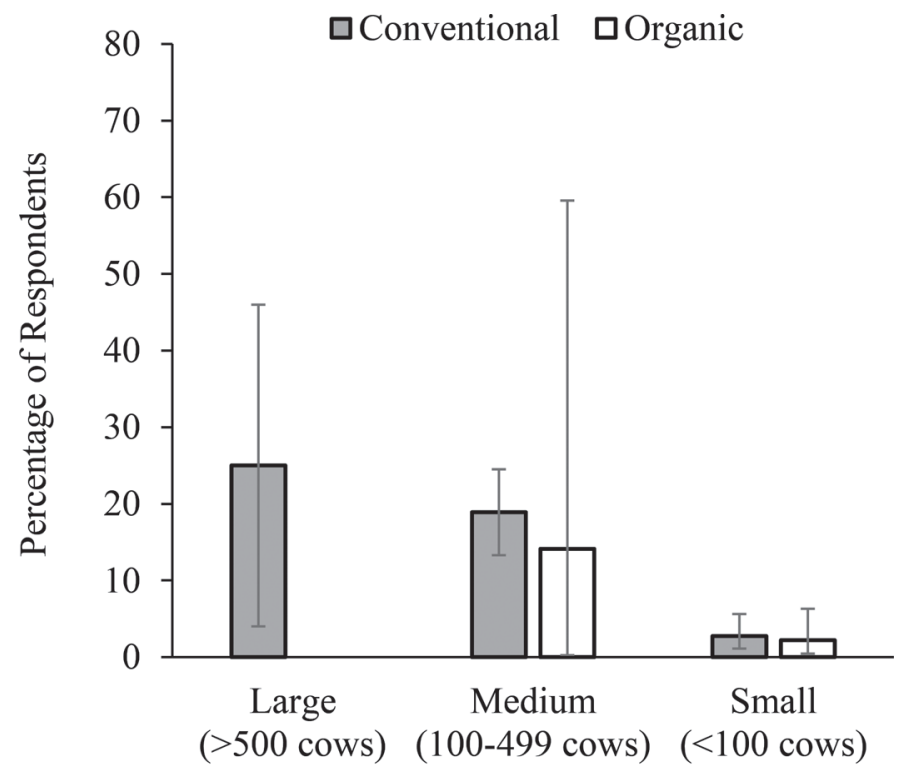

\section{Herd Size}

Figure 2. Percentage $( \pm \mathrm{SE})$ of conventional and organic dairy producers that reported measuring colostrum quality. Responses differed significantly $(P<0.0001)$ by herd size. One large organic herd $(>500$ cows) provided survey data; this herd reported measuring colostrum quality. pensive. On the other hand, for conventional producers disagreeing with the usefulness of measuring colostrum quality, over half $(53 \%, 11 / 21)$ agreed that the process is time-consuming. Conventional producers were less likely than organic producers to agree that measuring colostrum quality is time-consuming $(\mathrm{OR}=0.59,95 \%$ $\mathrm{CI}=0.38-0.92)$. In other words, nearly twice as many $(29 \%, 43 / 149)$ organic producers believed measuring colostrum quality was time-consuming compared with $18 \%(73 / 413)$ of conventional producers. Job training and cost of the equipment were not associated with whether herds measured colostrum quality (Table 4).

\section{Colostrum Delivery Method}

To identify how calves receive their first feeding of colostrum, producers were asked to specify whether calves suckle the dam, are hand-fed colostrum or colostrum replacer, or receive colostrum by some other method (Table 1). Among conventional producers, $13 \%$ (56/448) of respondents reported calves suckle the dam for their first colostrum feeding compared with $38 \%$ $(69 / 171)$ of certified organic producers. Sixty-eight percent $(304 / 448)$ of conventional producers reported calves are hand-fed colostrum or colostrum replacer, whereas only $30 \%(50 / 171)$ of organic producers reported hand-feeding calves colostrum. Lastly, 17 (77/448) and $30 \%(48 / 171)$ of conventional and organic producers, respectively, reported a combination of suckling and hand-feeding for the first feeding of colostrum.

Colostrum delivery method differed $(P<0.0001)$ by timing of cow-calf separation (Figure 3 ). For example, $85 \%$ of conventional $(255 / 299)$ and organic (39/48) producers, respectively, reported early cow-calf separation for calves hand-fed colostrum. However, significantly fewer conventional $(27 \%, 14 / 52)$ and organic $(15 \%$, $11 / 67$ ) producers reported early separation when calves suckle the dam for the first feeding. In other words, duration before cow-calf separation (e.g., delayed and 


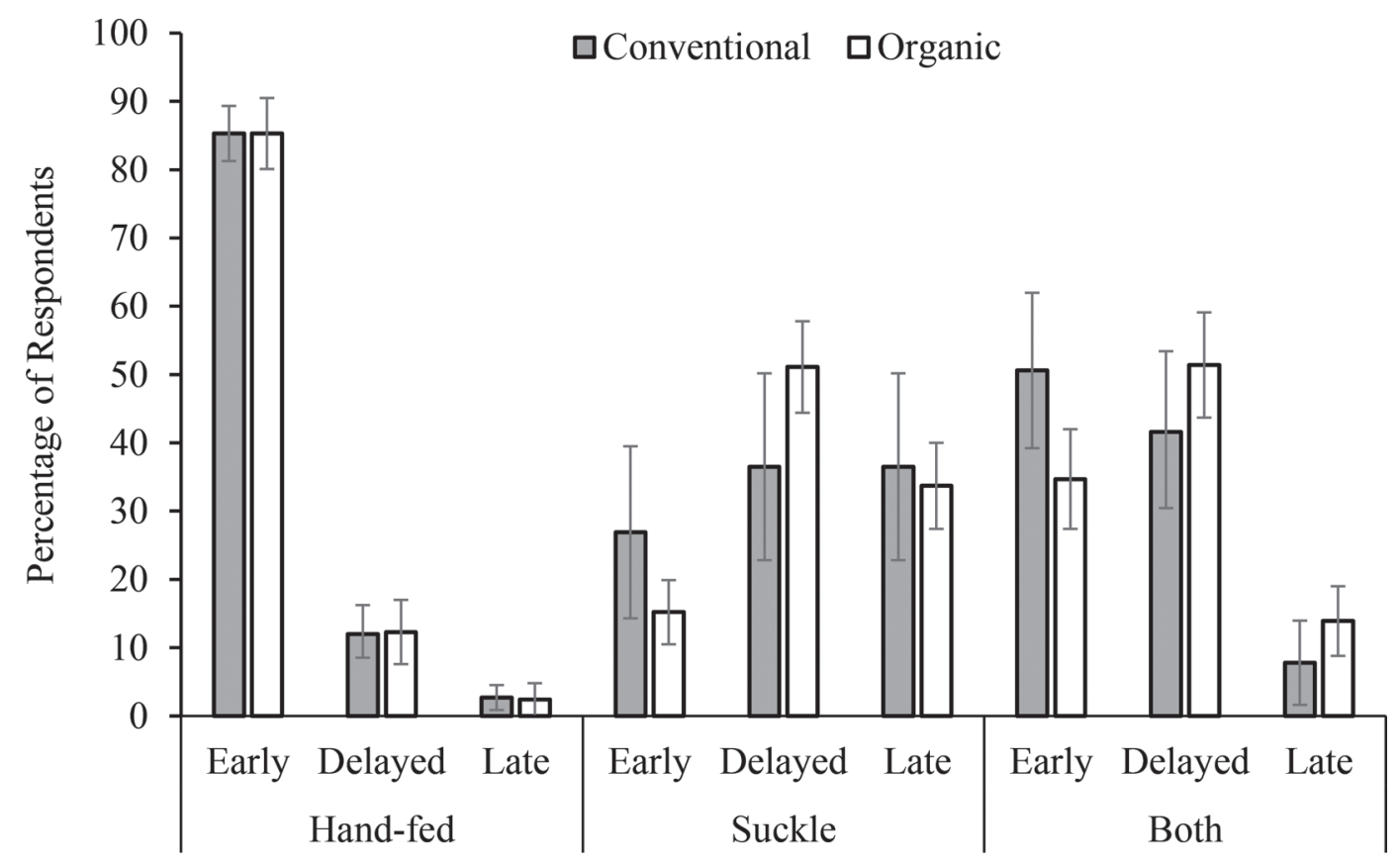

Figure 3. Percentage $( \pm \mathrm{SE})$ of conventional and organic dairy producers that reported early $(<6 \mathrm{~h})$, delayed $(6-18 \mathrm{~h})$, or late $(>18 \mathrm{~h}$ after birth) cow-calf separation by colostrum delivery method. Colostrum delivery method differed $(P<0.0001)$ by timing of cow-calf separation.

late separation versus early separation) increased when producers reported calves to suckle the first feeding of colostrum. Thus, independent of herd type, the majority of producers that reported separating the calf from the dam within $6 \mathrm{~h}$ after birth hand-fed the first feeding of colostrum, whereas producers that reported the calf to suckle the dam reported timing before cow-calf separation $>6$ h after birth.

\section{Attitudes on Colostrum Delivery Method}

Attitudes on the delivery method for the first colostrum feeding for newborn calves differed $(P<0.0001)$ between conventional and organic producer respondents. For instance, the majority $(69 \%, 115 / 169)$ of organic producers agreed it is best for the calf if its first feeding of colostrum is from suckling its mother. However, only $25 \%(111 / 444)$ of conventional producers agreed with the same statement. Further, 16\% (69/440) of conventional producers agreed that allowing a calf to suckle colostrum is beneficial for the dam and $46 \%$ (204/440) disagreed. In contrast, $48 \%(82 / 167)$ of organic producers agreed with the previous statement and 15\% (24/167) disagreed. Thus, organic producers were more likely than conventional producers to agree that allowing the calf to suckle colostrum is beneficial for both the dam and calf. In addition, 68 (300/441) and $40 \%(67 / 169)$ of conventional and organic respondents, respectively, preferred calves to be hand-fed their first feeding of colostrum but agreed they may not arrive in time to do so.

\section{Vaccination for Respiratory Disease}

Forty-four percent (188/430) of conventional producers reported vaccinating their calves for respiratory disease compared with $14 \%(22 / 162)$ of organic producers (Table 1). Vaccination use also differed $(P<0.0001)$ by herd size, with large- and medium-sized herds being more likely to report vaccinating calves for respiratory disease compared with small-sized herds. Attitudes on vaccinating against respiratory disease were divergent between conventional and organic producers $(P<$ 0.0001). For instance, conventional producers generally agreed $(51 \%, 218 / 426)$ vaccines for respiratory disease in preweaned calves are effective; however, only $15 \%$ $(23 / 155)$ of organic producers agreed in their effectiveness. Few producers (conventional: 16\%, 68/427; organic: $15 \%, 23 / 155)$ agreed vaccines are expensive. Twenty-five (106/425) and $32 \%(51 / 153)$ of conventional and organic producers, respectively, agreed that vaccinating calves for respiratory disease is time-consuming. Lastly, only $3 \%(14 / 425)$ of conventional producers agreed that vaccination is harmful to the health of calves and $66 \%$ $(282 / 425)$ disagreed with this statement. In contrast, $14 \%(24 / 155)$ of organic producers agreed that vaccina- 
tions are harmful to calves health and 27\% (38/155) disagreed.

\section{DISCUSSION}

The objectives of our study were 2-fold: to assess the usage frequency of selected calf management practices within conventional and certified organic dairy operations and to investigate attitudinal differences between conventional and organic producers related to calf health and management. The results of our study demonstrated calf management practices differ between conventional and organic dairy operations, and producers from different operation types largely disagreed on the benefits and risks of cow-calf separation, colostrum management, and vaccination for respiratory disease.

There were strengths and limitations to this survey methodology. A high response rate was achieved through a combination of mailed reminders and survey incentives to reduce the potential for nonresponse bias (tailored design method; Dillman et al., 2009). Because the majority of respondents were herd owners, they were likely the individuals making decisions on management practices on the farm, as opposed to employees or other farm personnel. Thus, we are confident that the attitudes of the respondents are indicative of the reported management practices. Nonetheless, selfreported attitudes are prone to the social desirability bias or the tendency to report what is correct or socially acceptable (Fisher, 1993). To mitigate this potential bias, participants were able to respond to the survey confidentially, and because most respondents were owners of the operation, this bias was not magnified as it might have been if employees were the majority of respondents; employees often believe their employers have the ability to gain access to responses, inflating the self-report bias (Donaldson and Grant-Vallone, 2002). Herd profiles (e.g., herd size) were not available to aid farm selection; thus, only $2.5(9 / 361)$ and $4.6 \%$ $(12 / 259)$ of respondents from Ohio and Michigan, respectively, reported herd sizes over 500 cows. Although this limited our ability to make comparisons between herd sizes and provide estimates for large herds in the United States, this study population is comparable to the herd distributions of Ohio and Michigan (USDA, 2012). The NOP provides regulations for certified organic producers, including healthcare practices. This may explain, at least in part, some of the findings presented here. Furthermore, our study did not encompass all aspects of calf health and management, such as colostrum harvesting, quantity and timing of colostrum administration, failure of passive transfer, or general vaccination usage; nevertheless, it provides novel in- formation pertaining to producer attitudes and usage frequency of selected calf management practices among conventional and certified organic producers.

The results of our study suggest significant and meaningful differences in attitudes between conventional and organic dairy producers on cow-calf separation, which are likely to affect adoption of specific management practices. The majority of operations reported separating the calf from the dam within $6 \mathrm{~h}$ of birth; however, nearly twice as many organic compared with conventional producers reported separation 6 to $12 \mathrm{~h}$ after birth. Immediate separation of the calf from the dam is common practice in the United States (USDA, 2008) and Canada (Vasseur et al., 2010). However, because separation is perceived by the public to be an animal welfare concern (Ventura et al., 2013), alternatives to immediate separation continue to investigated (Wagner et al., 2012; Johnsen et al., 2015). Further, very recent research has shown those in favor of late separation (e.g., days or weeks after birth) place emphasis on natural rearing and the emotional consequences of separation (Busch et al., 2017). In contrast, those in favor of early separation (e.g., hours after birth) emphasize the disadvantages associated with later separation (e.g., distress associated with severing this bond) (Busch et al., 2017). Conventional producer supporters of early $(<6 \mathrm{~h}$ after birth) cow-calf separation were more likely than organic producers to agree that early separation is beneficial to the cow and calf; other researchers have cited early separation to benefit the health of cows and calves (Whittington and Windsor, 2009; Vasseur et al., 2010). Lund (2006), however, suggested organic operations place emphasis on the natural living component of animal welfare, which includes the ability of an animal to perform natural behaviors (e.g., maternal behavior, calves to nurse the dam). In contrast, conventional producers were as likely to agree the calving process should be natural; yet, the term natural may have been interpreted differently by conventional (e.g., no necessary interventions) relative to organic (e.g., natural setting and delayed separation) producers. Thus, cow-calf separation practices among conventional producers may be most driven by the desire to improve calf health, whereas separation practices among organic producers may be designed to incorporate natural behavior. Nevertheless, additional research directly addressing producer values and motivations for cow-calf separation practices should be considered.

Few producers in our study reported using a colostrometer or refractometer to measure immunoglobulin concentration. Our estimates are somewhat lower than the $15.5 \%$ of all dairy herds previously reported in national-level studies within the United States (USDA, 
2016), but higher than an estimate from Canadian dairy herds, where zero of 115 producers reported measuring colostrum quality (Vasseur et al., 2010). Our study also demonstrated more conventional than organic producers believed measuring colostrum quality provides valuable information on feeding calves colostrum, and more organic than conventional producers believe it to be time-consuming. However, the majority of producers responded neutral to most attitudinal measures, regardless of herd type; neutral or ambivalent responses are likely to lead to behavioral change (Petty et al., 2006). Dairy extension programs must evolve to continue to meet the needs of a changing clientele base (Hutjens et al., 2004), and recent research has shown benchmarking (e.g., comparing one's own performance to others) specific outcomes associated with calf management leads to behavioral change that improves calf health and performance (Atkinson et al., 2017). Thus, these findings provide valuable information for extension educators, veterinarians, and consultants to develop conventional and organic producer-oriented programs, such as benchmarking programs that target the importance of measuring colostrum quality to dairy calf health and development.

Method of colostrum delivery differed between conventional and organic dairy producers in our study. The majority of conventional producer respondents handfed colostrum, whereas most organic producers either allowed calves to nurse the dam or provided colostrum via combination of hand-feeding and nursing. In comparison, 53,6 , and $41 \%$ of operations have been reported to provide the first feeding of colostrum to newborn calves through hand-feeding, nursing, or a combination of hand-feeding and nursing (USDA, 2016). The method used to supply colostrum to newborn calves can influence the quantity of colostrum consumed, thus affecting the absorption of immunoglobulins and the health and survival of the calf (Besser et al., 1991). Hand-feeding colostrum is sometimes preferred to nursing the dam, as this method allows producers to closely monitor quantity and quality of colostrum consumed (USDA, 2016); yet, our research provides evidence that few producers actually measure colostrum quality regardless of colostrum delivery method. It must also be noted that producers may still monitor colostrum intake if calves are left to nurse the dam; however, this was not addressed by the current study. Studies in support of leaving the calf with the dam to nurse have shown benefits for calf health (Weary and Chua, 2000) and growth (Flower and Weary, 2001). Thus, when properly managed, different methods of colostrum delivery can successfully promote calf health and development. Further, although this was not directly assessed in the current study, observed differences between conventional and organic producers may stem from differences in producer attitudes on this practice. In other words, conventional producers may choose to hand-feed colostrum to more accurately monitor colostrum intake to safeguard calf health, and organic dairy producers may leave the calf to nurse the dam as this is a natural behavior. This idea, however, warrants further research.

Approximately 44 and $14 \%$ of conventional and organic herds, respectively, reported using respiratory vaccines in calves. We expected a higher percentage of organic producers to report vaccination against respiratory disease, as organic management in the United States (e.g., the NOP) promotes preventative measures to handle disease (Ruegg, 2009). In contrast to our results, Stiglbauer et al. (2013) reported $67 \%$ of organic producers vaccinated calves for any disease, compared with $100 \%$ of conventional grazing producers and $98 \%$ of conventional nongrazing producers. The most common vaccines administered to preweaned heifer calves are infectious bovine rhinotracheitis, parainfluenza type-3, and bovine respiratory syncytial virus, and current estimates in the United States for vaccination use for any disease in calves are 49\% (USDA, 2016). Vaccines were perceived as more effective by conventional than organic producers in the current study, which may partially explain the different usage practices between herds; yet, the United States Food and Drug Administration must license a vaccine to ensure its safety and effectiveness before it can be used in the United States. In addition, because organic producers manage their herds differently than conventional producers, it is possible that respiratory disease occurs less frequently and leads to the opinion that vaccines are not necessary. For example, organic herds in Sweden have reported lower seroprevalence of bovine respiratory syncytial virus compared with conventional herds (Bidokhti et al., 2009). This idea, however, warrants further investigation. Regardless, these results suggest ideological opposition to the use of vaccines among organic producers, and producer attitudes on the safety and efficacy of respiratory vaccines may influence their reluctance to adopt this management practice.

\section{CONCLUSIONS}

The results of this study suggest significant and meaningful differences in attitudes and practices between conventional and organic dairy producers on key management practices related to calf health. Likewise, conventional and organic producers largely disagreed on the benefits and risks of common calf management practices. Specifically, the attitudes of conventional and 
organic producers strongly diverged on management practices surrounding cow-calf separation and colostrum delivery. Reported measure of colostrum quality was low among both herd types; thus, future extension efforts should focus on the importance of measuring colostrum quality to dairy calf health and development. Far fewer organic than conventional producers vaccinated calves for respiratory disease, and vaccine reluctance among organic producers may be influenced by perceived vaccine effectiveness and safety. Together, this information can be used to develop producer-oriented programs to address specific attitudes to implement sound management practices to promote calf health and development. Additional research should focus on producer attitudes related to additional calf management practices (e.g., attitudes on colostrum and milk allowance, calf housing and environment, and time for cow-calf separation) and their association with morbidity, mortality, and performance of calves and dams.

\section{ACKNOWLEDGMENTS}

This research was supported by the National Institute of Food and Agriculture, USDA (award number 201338640-20901) through the North Central Region Sustainable Agriculture Research and Education (SARE) program (sub award number LNC13-351), administered through the University of Minnesota (St. Paul).

\section{REFERENCES}

Atkinson, D. J., M. A. G. von Keyserlingk, and D. M. Weary. 2017. Benchmarking passive transfer of immunity and growth in dairy calves. J. Dairy Sci. 100:3773-3782. https://doi.org/10.3168/jds 2016-11800

Besser, T. E., C. C. Gay, and L. Pritchett. 1991. Comparison of three methods of feeding colostrum to dairy calves. J. Am. Vet. Med. Assoc. 198:419-422.

Bidokhti, M. R., M. Tråvén, N. Fall, U. Emanuelson, and S. Alenius. 2009. Reduced likelihood of bovine coronavirus and bovine respiratory syncytial virus infection on organic compared to conventional dairy farms. Vet. J. 182:436-440.

Boogaard, B. K., B. B. Bock, S. J. Oosting, and E. Krogh. 2010. Visiting a farm: An exploratory study of the social construction of animal farming in Norway and the Netherlands based on sensory perception. Int. J. Sociol. Agric. Food 17:24-50.

Busch, G., D. M. Weary, A. Spiller, and M. A. G. von Keyserlingk. 2017. American and German attitudes towards cow-calf separation on dairy farms. PLoS One 12:e0174013.

Clopper, C. J., and E. S. Pearson. 1934. The Use of confidence or fiducial limits illustrated in the case of the binomial. Biometrika $26: 404$.

Dargatz, D. A., and G. W. Hill. 1996. Analysis of survey data. Prev. Vet. Med. 28:225-237.

Dillman, D. A., J. D. Smyth, and L. M. Christian. 2009. Internet, Mail, and Mixed-Mode Surveys: Tailored Design Method. 3rd ed., John Wiley \& Sons Inc., Hoboken, NJ.

Donaldson, S. I., and E. J. Grant-Vallone. 2002. Understanding selfreport bias in organizational behavior research. J. Bus. Psychol. $17: 245-260$.
Fisher, R. J. 1993. Social desirability bias and the validity of indirect questioning. J. Consum. Res. 20:303-315.

Flower, F. C., and D. M. Weary. 2001. Effects of early separation on the dairy cow and calf: 2 . Separation at 1 day and 2 weeks after birth. Appl. Anim. Behav. Sci. 70:275-284.

Furman-Fratczak, K., A. Rzasa, and T. Stefaniak. 2011. The influence of colostral immunoglobulin concentration in heifer calves' serum on their health and growth. J. Dairy Sci. 94:5536-5543.

Gillespie, J., S. Kim, and K. Paudel. 2007. Why don't producers adopt best management practices? An analysis of the beef cattle industry. Agric. Econ. 36:89-102.

Godden, S. 2008. Colostrum management for dairy calves. Vet. Clin. Food. Anim. 24:19-39.

Habing, G., C. Djordjevic, G. M. Schuenemann, and J. Lakritz. 2016. Understanding antimicrobial stewardship: Disease severity treatment thresholds and antimicrobial alternatives among organic and conventional calf producers. Prev. Vet. Med. 130:77-85.

Hosmer, D. E., S. Lemeshow, and R. X. Sturdivant. 2013. Applied Logistic Regression. 3rd ed., John Wiley \& Sons Inc., Hoboken, NJ.

Hutjens, M. F., T. P. Lyons, and K. A. Jacques. 2004. Meeting the educational needs of dairy clientele in 2020. Pages 205-210 in Proc. Nutritional Biotechnology in the Feed and Food Industries; Proc. 20th Alltech Symposium. Nottingham University Press, Nottingham, UK.

Johnsen, J. F., K. Ellingsen, A. M. Grøndahl, K. E. Bøe, L. Lidfors, and C. M. Mejdell. 2015. The effect of physical contact between dairy cows and calves during separation on their post-separation behavioural response. Appl. Anim. Behav. Sci. 166:11-19.

Kraus, S. J. 1995. Attitudes and the prediction of behavior: A meta-analysis of the empirical literature. Pers. Soc. Psychol. Bull. $21: 58-75$.

Lund, V. 2006. Natural living - A precondition for animal welfare in organic farming. Livest. Sci. 100:71-83.

McGuirk, S. M. 2008. Disease management of dairy calves and heifers. Vet. Clin. North Am. Food Anim. Pract. 24:139-153.

Petty, R. E., Z. L. Tormala, P. Briñol, and W. B. G. Jarvis. 2006 Implicit ambivalence from attitude change: An exploration of the PAST model. J. Pers. Soc. Psychol. 90:21-41.

Rahelizatovo, N. C., and J. M. Gillespie. 2004. The adoption of bestmanagement practices by Louisiana dairy producers. J. Agric. Appl. Econ. 36:229-240.

Roth, J. 2011. Veterinary vaccines and their importance to animal health and public health. Procedia Vaccinol. 5:127-136.

Ruegg, P. L. 2009. Management of mastitis on organic and conventional dairy farms. J. Anim. Sci. 87:43-55.

Stiglbauer, K. E., K. M. Cicconi-Hogan, R. Richert, Y. H. Schukken, P. L. Ruegg, and M. Gamroth. 2013. Assessment of herd management on organic and conventional dairy farms in the United States. J. Dairy Sci. 96:1290-1300.

Svensson, C., K. Lundborg, U. Emanuelson, and S.-O. Olsson. 2003. Morbidity in Swedish dairy calves from birth to 90 days of age and individual calf-level risk factors for infectious diseases. Prev. Vet. Med. 58:179-197. https://doi.org/10.1016/S0167-5877(03)00046 $-1$.

Uetake, K. 2013. Newborn calf welfare: A review focusing on mortality rates. Anim. Sci. J. 84:101-105.

USDA. 2008. Dairy 2007, Part III: Reference of Dairy Cattle Health and Management Practices in the United States. USDA-NAHMS. Fort Collins, CO.

USDA. 2010. Dairy 2007, Heifer Calf Health and Management Practices on U.S. Dairy Operations. USDA-APHIS-VS, CEAH. Fort Collins, CO

USDA. 2012. USDA 2012 Volume 1, Chapter 1: State Level Data. Accessed Jan. 5, 2017. https://www.agcensus.usda.gov/Publications/ 2012/Full_Report/Volume_1,_Chapter_1_State_Level/Ohio/.

USDA. 2016. Dairy 2014, Dairy Cattle Management Practices in the United States, 2014. USDA-APHIS-VS-CEAH-NAHMS, Fort Collins, CO.

Vasseur, E., F. Borderas, R. I. Cue, D. Lefebvre, D. Pellerin, J. Rushen, K. M. Wade, and A. M. De Passillé. 2010. A survey of dairy 
calf management practices in Canada that affect animal welfare. J. Dairy Sci. 93:1307-1315.

Ventura, B. A., M. A. G. von Keyserlingk, C. A. Schuppli, and D. M. Weary. 2013. Views on contentious practices in dairy farming: The case of early cow-calf separation. J. Dairy Sci. 96:6105-6116.

Ventura, B. A., M. A. G. von Keyserlingk, H. Wittman, and D. M. Weary. 2016. What difference does a visit make? Changes in animal welfare perceptions after interested citizens tour a dairy farm. PLoS One 11:e0154733.

Wagner, K., K. Barth, R. Palme, A. Futschik, and S. Waiblinger. 2012. Integration into the dairy cow herd: long-term effects of mother contact during the first twelve weeks of life. Appl. Anim. Behav. Sci. 141:117-129.

Weary, D. M., and B. Chua. 2000. Effects of early separation on the dairy cow and calf: 1 . Separation at $6 \mathrm{~h}, 1$ day and 4 days after birth. Appl. Anim. Behav. Sci. 69:177-188.
Whittington, R. J., and P. A. Windsor. 2009. In utero infection of cattle with Mycobacterium avium ssp. paratuberculosis: A critical review and meta-analysis. Vet. J. 179:60-69.

Willock, J., I. J. Deary, G. Edwards-Jones, G. J. Gibson, M. J. McGregor, A. Sutherland, J. B. Dent, O. Morgan, and R. Grieve. 1999. The role of attitudes and objectives in farmer decision making: business and environmentally-oriented behaviour in Scotland. J. Agric. Econ. 50:286-303.

Windeyer, M. C., K. E. Leslie, S. M. Godden, D. C. Hodgins, K. D. Lissemore, and S. J. LeBlanc. 2014. Factors associated with morbidity, mortality, and growth of dairy heifer calves up to 3 months of age. Prev. Vet. Med. 113:231-240.

Zwald, A. G., P. L. Ruegg, J. B. Kaneene, L. D. Warnick, S. J. Wells, C. Fossler, and L. W. Halbert. 2004. Management practices and reported antimicrobial usage on conventional and organic dairy farms. J. Dairy Sci. 87:191-201. 